\title{
Uma análise teórica sobre a temática hídrica em livros didáticos de Biologia do PNLD 2018
}

\author{
João Paulo Cunha de Menezes ${ }^{1}$ \\ Simone Silva da Fonseca ${ }^{2}$ \\ Ana Júlia Lemos Alves Pedreira ${ }^{3}$
}

\begin{abstract}
RESUMO
A água é um recurso limitado e que requer cuidados. As abordagens generalistas presentes nos livros didáticos podem parecer distantes da realidade do aluno, sendo, então, importante a contextualização e enriquecimento dessas. Desta forma, este trabalho teve como objetivo analisar os livros didáticos de Biologia sugeridos pelo Programa Nacional do Livro e do Material Didático 2018, buscando apreender a forma como os conhecimentos sobre o tema "Recursos Hídricos" se apresentam e estão relacionados à temática ambiental. Os resultados encontrados indicam que os livros didáticos são instrumentos que podem auxiliar professores e estudantes na aprendizagem, mas requerem um material de apoio como ferramenta sensibilizadora, devido ao fato de que nos livros didáticos não há uma abordagem minuciosa sobre a questão hídrica, que desperte a participação e reflexão sobre o uso da água e maneiras de minimizar o impacto do ser humano na exploração desse recurso.
\end{abstract}

PALAVRAS-CHAVE: Crise hídrica. Programa Nacional do Livro e Material Didático. Livros didáticos

A theoretical analysis of the water theme in some PNLD Biology textbooks 2018

\footnotetext{
${ }^{1}$ Doutor em Recursos Hídricos. Universidade de Brasília, Brasília, Distrito Federal Brasil. https://orcid.org/00000002-2566-3957.jpaulo_bio@hotmail.com.

${ }^{2}$ Mestre em Ensino de Biologia. Universidade de Brasília, Brasília, Distrito Federal Brasil. https://orcid.org/00000002-2076-7853. simone.licbio@yahoo.com.br.

${ }^{3}$ Doutora em Educação. Universidade de Brasília, Brasília, Distrito Federal Brasil. https://orcid.org/0000-0003-21241789.anajuliapedreira@unb.br.
} 


\begin{abstract}
Water is a limited resource that requires care. The generalist approaches present in the textbooks may seem distant from the reality of the student, so it is important to contextualize and enrich them. Thus, this work aimed to analyze the textbooks of Biology suggested by the National Program of Books and Didactic Material 2018, seeking to learn how the knowledge on the theme "Water Resources" are presented and are related to the environmental theme. The results found were positive, since they indicate that textbooks are instruments that can assist teachers and students in learning, but require a support material as a sensitizing tool, due to the fact that the textbooks do not have a detailed approach on the water issue, which awakens participation and reflection on the use of water and ways to minimize the impact human being on the exploration of this resource.
\end{abstract}

KEYWORDS: Water crisis. National Program of the Book and Didactic Material. Schoolbooks

Um análisis teórico del tema del agua en algunos libros de texto de biologia de PNLD 2018

\title{
RESUMEN
}

El agua es un recurso limitado que requiere cuidados. Los enfoques generalistas presentes en los libros de texto pueden parecer distantes de la realidad del estudiante, por lo que es importante contextualizarlos y enriquecerlos. Así, este trabajo tenía como objetivo analizar los libros de texto de Biología sugeridos por el Programa Nacional de Libros y Material Didáctico 2018, buscando aprender cómo el conocimiento sobre el tema "Recursos Hídricos" se presentan y se relacionan con el tema ambiental. Los resultados encontrados fueron positivos, ya que indican que los libros de texto son instrumentos que pueden ayudar a profesores y alumnos en el aprendizaje, pero requieren un material de apoyo como herramienta de sensibilización, debido a que en los libros de texto no existe un enfoque detallado sobre el tema del agua, lo que despierta la participación y la reflexión sobre el uso del agua y las formas de minimizar el impacto ser humano en la explotación de este recurso.

PALABRAS CLAVE: Crisis del agua. Programa Nacional del Libro y Material Didáctico. Libros de texto 


\section{Introdução}

A água é um recurso natural precioso e necessário para a sobrevivência dos seres vivos. Esse recurso é limitado, e, com o crescimento da população, a demanda por ele aumenta. Não bastando esse crescimento, um estilo de vida mais consumista, bem como o desperdício em variadas formas contribuem para ameaçar a disponibilidade desse recurso para todos que precisam dele. Segundo Barbosa (2014) tudo o que comemos necessita de água para se desenvolver, tornando a agricultura uma grande usuária de água.

Ao alimentar o mundo e produzir grande quantidade de culturas para fins variados, como algodão, borracha e óleos industriais, a atividade responde por nada menos do que $70 \%$ do consumo mundial do recurso (BRABOSA, 2014, p. 66).

Diante disso, o desperdício desse recurso pode ocorrer quando compramos mais do que precisamos, como alimentos, bens de consumo ou quando não nos atentamos à vazamentos de água em casa ou consumimos mais do que deveríamos desse recurso.

A informação acima converge com o que aconteceu com o Distrito Federal (DF) em 2016 e o atual estado de alerta para o consumo consciente da água. Essa região, pela primeira vez na história, enfrentou um cenário profundo de crise hídrica. Isso interferiu diretamente no uso da água, com inserção de políticas de racionamento, redução de pressão, restrição de uso a agricultores e comerciantes, aumento das tarifas, entre outros (ADASA, 2016). Neste contexto, não pode ocorrer omissão diante de tal crise, e a educação da população poderia ser considerada um caminho para a resolução do problema.

Nesse sentido, Martins e Guimarães (2002, p. 2) afirmam que "a escola precisa atuar como instrumento de mudança, de busca de ideal possível, e de luta pela qualidade de vida da sociedade". A fim de auxiliar no 
processo de ensino e de aprendizagem, a educação brasileira conta com o livro didático, material que segue critérios estabelecidos pelos editais do Programa Nacional do Livro e do Material Didático (PNLD), que, por sua vez, são fundamentados de acordo com a legislação, além de serem avaliados por especialistas das diversas áreas do conhecimento. Segundo Otalara e Carvalho (2011), o livro didático é um material de fácil acesso pelos professores e alunos, permitindo ser usado para consulta ou como fonte bibliográfica. Logo, este necessita trabalhar questões atuais, como a crise da água, de forma que possibilite que os estudantes e professores pensem sobre esse assunto de maneira crítica e analítica.

Diante dessa importância, os livros didáticos necessitam tratar o assunto de forma ampla, considerando também fatores culturais e sociais. Souza e Rocha (2017, p.325) afirmam que

[...] frequentemente o que é escrito nos livros didáticos encontra barreiras de natureza epistemológica, seja esbarrando na complexidade dos fenômenos científicos ou na falta de linguagem e de outros recursos que tornem acessíveis as informações para os alunos.

Em adição, Martins e Guimarães (2002, p. 109) asseveraram que "a organização dos conteúdos nos livros didáticos não contribui para a construção de uma visão holística do ambiente". Vale observar que essa afirmativa caminha para a direção oposta especificada no Currículo da Educação Básica do Distrito Federal, Currículo em Movimento, que estimula práticas pedagógicas reflexivas, questionadores, enfim, práticas que incitem o protagonismo no processo educativo e no processo de formação da cidadania (BRASIL, 2013 p. 24).

De acordo com Silva (2016, p.113) "a estrutura do livro didático, na maioria das vezes, apresenta o conteúdo conceitual de forma linear". A mesma autora sugere a necessidade de materiais didáticos que sirvam de 
apoio para a elaboração e implementação de propostas de intervenção. Outros autores também ressaltam que os livros didáticos são ferramentas importantes em sala de aula e que a abordagem hídrica nestes, para que possibilite a análise mais profunda sobre essa temática, necessita levar em consideração os fatores históricos, sociais e práticos da sociedade, fatores importantes para a construção do conhecimento (SILVA; SILVA, 2017). Ainda para os autores citados, é frequente que o livro didático não ultrapasse muito o conteúdo do ciclo da água presente nos ciclos biogeoquímicos para a realidade dos estudantes.

Desta maneira, abordar de forma muito sumária a questão da água pode trazer uma visão superficial e simplista da real problemática da crise hídrica (PASSERIA et al., 2017). Levar essa temática para a sala de aula deve ser feito de forma que o estudante perceba a necessidade de mudança de hábito e de ações socioambientais. É necessário trabalhar o conhecimento sob a perspectiva de significado para a vida, e para isso é imperativo desenvolver habilidades e atitudes que caminhem para a questão da cidadania como algo essencial (CULPI, 2016; GOMES; NAKAYAMA, 2017).

Otalara e Carvalho (2011) evidenciam que há preocupação por parte dos autores dos livros didáticos em tentarem incorporar aspectos que são próximos do cotidiano dos estudantes, procurando auxiliar na compreensão de conteúdos ligados ao tema água. Apesar disso, para os autores citados, a abordagem da temática ainda é rasa, sem o aprofundamento dos fatores influenciadores e relacionados à disponibilidade do recurso hídrico, pois

[...] os exemplos identificados nos livros, permitem afirmar que esses parecem procurar auxiliar na compreensão de conteúdos ligados ao tema água, o que deve ser visto como um esforço válido, contudo, essas tentativas poderiam ser empregadas para se aprofundar na abordagem do tema, ampliando a própria ideia de cotidiano, explorando possíveis relações entre a dimensão local e a dimensão global da temática ambiental e trabalhando as relações 
entre os conhecimentos relacionados ao senso comum, à ciência ou à cultura (OTALARA; CARVALHO, 2011, p. 11).

Diante disso, a ação contra o uso perdulário da água precisa vir da análise crítica, da problematização, da visão de importância hídrica e a apreciação minuciosa sobre o tema. Com essa perspectiva, este trabalho buscou examinar as coleções dos livros didáticos de Biologia aprovados e disponibilizados pelo Programa Nacional do Livro e do Material Didático (PNLD) 2018 com base na análise teórica apresentada.

\section{Metodologia}

Para a realização da pesquisa qualitativa dos livros didáticos, foi realizada a análise de conteúdo, sendo adaptados os procedimentos da metodologia proposta por Vasconcelos e Souto (2003) em que avaliaram a abordagem teórica dos livros didáticos de Biologia. Os autores estabelecem critérios voltados para o enfoque científico e a correlação deste com o nível de cognição, do estímulo à problematização e o nível de contextualização do conhecimento. Também foram analisadas as atividades propostas nos livros. Perante o que foi exposto, o intuito desta pesquisa não é desqualificar os livros didáticos, mas sim verificar como é a abordagem da temática hídrica nos livros didáticos, bem como os manuais do professor neles contidos.

\section{Seleção dos livros didáticos}

Os livros didáticos selecionados foram as dez coleções de Biologia sugeridas pelo PNLD 2018 do Ensino Médio, cada coleção possui três volumes (Volume 1, 2 e 3), mas somente dez destes volumes abordavam a questão da água. Estes foram identificados por numerações para facilitar a leitura no decorrer do texto, conforme o Quadro 1, a seguir. Neste quadro, estão presentes somente os volumes que abordam a questão hídrica, sendo desconsiderados os outros volumes. 
Quadro 1: Descrição dos livros didáticos analisados e a identificação numérica que será adotada neste trabalho.

\begin{tabular}{|c|c|c|c|c|c|}
\hline Identificação & Título da coleção & Autor (es) & Editora & $\begin{array}{c}\text { Ano de } \\
\text { publicação }\end{array}$ & $\begin{array}{c}\text { Volumes } \\
\text { analisados }\end{array}$ \\
\hline Livro 1 & Biologia moderna & $\begin{array}{c}\text { José Mariano Amabis e } \\
\text { Gilberto rodrigues } \\
\text { Martho }\end{array}$ & Moderna & 2016 & 3 \\
\hline Livro 2 & $\begin{array}{c}\text { Biologia: novas } \\
\text { bases }\end{array}$ & Nélio Bizzo & IBEP & 2016 & 3 \\
\hline Livro 3 & Biologia & $\begin{array}{c}\text { César da Silva Jr.; } \\
\text { Sezar Sasson e Nelson } \\
\text { Caldini Jr. }\end{array}$ & Saraiva & 2016 & 1 \\
\hline Livro 4 & $\begin{array}{l}\text { Biologia: ser } \\
\text { protagonista }\end{array}$ & $\begin{array}{l}\text { Antônio Carlos } \\
\text { Bandouk }\end{array}$ & SM & 2016 & 3 \\
\hline Livro 5 & $\begin{array}{l}\text { Biologia: unidade } \\
\text { e diversidade }\end{array}$ & José Arnaldo Favaretto & FTD & 2016 & 3 \\
\hline Livro 6 & Biologia hoje & $\begin{array}{l}\text { Sérgio Linhares; } \\
\text { Fernando } \\
\text { Gewandsznajder e } \\
\text { Helena Pacca }\end{array}$ & Ática & 2016 & 3 \\
\hline Livro 7 & $\begin{array}{l}\text { \# Contato } \\
\text { Biologia }\end{array}$ & $\begin{array}{l}\text { Marcela Ogo e } \\
\text { Leandro Goddy }\end{array}$ & Quinteto & 2016 & 3 \\
\hline Livro 8 & Bio & $\begin{array}{c}\text { Sônia Lopes e Sérgio } \\
\text { Rosso }\end{array}$ & Saraiva & 2016 & 1 \\
\hline Livro 9 & Biologia & Vivian L. Mendonça & AJS & 2016 & 1 \\
\hline Livro 10 & $\begin{array}{l}\text { Conexões com a } \\
\text { Biologia }\end{array}$ & $\begin{array}{l}\text { Miguel Thompson e } \\
\text { Eloci Peres Rios }\end{array}$ & Moderna & 2016 & 1 \\
\hline
\end{tabular}

Fonte: Autores

Foram avaliadas as seguintes dimensões dos livros didáticos: o conteúdo teórico e as atividades propostas. Cada dimensão avaliada foi constituída por critérios que eram identificados como $\mathrm{C} 1$ para o critério 1 , C2 para o critério 2 e assim por diante. A dimensão do conteúdo teórico possui 7 critérios (C1-C7), em adição, foi analisado as atividades propostas presentes nos livros, 7 critérios (C8-C14).

Os critérios abrangem os elementos básicos necessários para uma melhor compreensão e visão ampla da questão hídrica. Cada critério foi 
subdividido em itens para estudo (Quadro 2). Os critérios foram considerados explícitos quando os itens estudados estavam claramente mencionados e expostos, apresentando, por exemplo, dados, gráficos, fornecendo exemplos concretos no corpo do texto. Foram caracterizados como implícitos quando deixaram as ideias subentendidas, mas sem se apresentarem, propriamente, escritos no texto, não havendo dados claros no decorrer da leitura do capítulo (VASCONCELOS; SOUTO, 2003). Foram classificados como ausentes, os critérios que não se apresentaram de forma alguma no texto.

Quadro 2: Descrição dos critérios utilizados para analisar o conteúdo teórico nos livros didáticos.

\begin{tabular}{|c|c|c|}
\hline $\begin{array}{c}\text { Dimensão avaliada nos livros } \\
\text { didáticos de Biologia PNLD } \\
2018\end{array}$ & Critérios em análise & $\begin{array}{l}\text { Estudo de cada } \\
\text { critério }\end{array}$ \\
\hline \multirow{15}{*}{ Conteúdo teórico } & \multirow{3}{*}{$\begin{array}{l}\text { C1. Identifica o ser humano como um dos } \\
\text { influenciadores do ciclo da água }\end{array}$} & I.Explícito \\
\hline & & II. Implícito \\
\hline & & III. Ausente \\
\hline & \multirow{3}{*}{ C2. A influência do relevo sobre o ciclo da água } & I. Explícito \\
\hline & & II. Implícito \\
\hline & & III. Ausente \\
\hline & \multirow{3}{*}{$\begin{array}{l}\text { C3. Influência da ocupação do solo na preservação } \\
\text { das nascentes }\end{array}$} & I. Explícito \\
\hline & & II. Implícito \\
\hline & & III. Ausente \\
\hline & \multirow{3}{*}{ C4. Influência do crescimento da população } & I. Explícito \\
\hline & & II. Implícito \\
\hline & & III. Ausente \\
\hline & \multirow{2}{*}{ C5. Aborda meios de economia de água } & I. Explícito \\
\hline & & II. Ausente \\
\hline & C6. Importância da gestão pública e cidadania & I. Explícito \\
\hline
\end{tabular}




\begin{tabular}{|l|l|l|}
\hline \multirow{2}{*}{} & & II. Implícito \\
\cline { 3 - 3 } & \multirow{2}{*}{ C7. Reflexão sobre o que é crise hídrica } & III. Ausente \\
\cline { 2 - 3 } & Outros: especificar & I. Explícito \\
\cline { 2 - 3 } & II. Ausente \\
\hline
\end{tabular}

Fonte: Autores

As atividades propostas, que compreendem os critérios 8 à C14, possuem os seguintes subitens específicos (Quadro 3).

Quadro 3: Descrição dos critérios utilizados para analisar as atividades propostas nos livros didáticos.

\begin{tabular}{|c|c|c|}
\hline $\begin{array}{c}\text { Dimensão avaliada nos livros } \\
\text { didáticos de Biologia PNLD } 2018\end{array}$ & Critérios em análise & Estudo de cada critério \\
\hline \multirow{15}{*}{ Atividades propostas } & \multirow{2}{*}{$\begin{array}{l}\text { C8. As atividades e suas } \\
\text { implicações }\end{array}$} & I. Abordam situações do cotidiano \\
\hline & & II. Não abordam situações do cotidiano \\
\hline & \multirow{2}{*}{$\begin{array}{l}\text { C9. Propostas de atividades } \\
\text { práticas }\end{array}$} & I. Existente \\
\hline & & II. Não existente \\
\hline & \multirow{2}{*}{$\begin{array}{l}\text { C10. Questões/exercícios ao } \\
\text { longo de cada capítulo/tema }\end{array}$} & I. Presente \\
\hline & & II. Ausente \\
\hline & \multirow{2}{*}{ C11. Enfoque das questões } & I. Enfoque multidisciplinar \\
\hline & & II. Enfoque unicamente biológico \\
\hline & \multirow{2}{*}{$\begin{array}{l}\text { C12. Problematização das } \\
\text { questões }\end{array}$} & I. Prioriza a problematização \\
\hline & & II. Não prioriza a problematização \\
\hline & \multirow{3}{*}{$\begin{array}{l}\text { C13. Recursos necessários } \\
\text { para a execução das } \\
\text { atividades propostas }\end{array}$} & I. Requer recursos de fácil obtenção \\
\hline & & $\begin{array}{l}\text { II. Não requer recursos de fácil } \\
\text { obtenção }\end{array}$ \\
\hline & & III. Não possui \\
\hline & \multirow{2}{*}{$\begin{array}{l}\text { C14. Grau de relação das } \\
\text { atividades com o conteúdo } \\
\text { trabalhado }\end{array}$} & I. Relacionado \\
\hline & & II. Não relacionado \\
\hline
\end{tabular}

Fonte: Autores 


\section{Resultados e Discussões}

Antes de expor a análise conforme os critérios apresentados na metodologia, cumpre observar que, em cada coleção de livros didáticos, há uma variação com respeito ao volume em que se encontra o módulo de Ecologia e com respeito aos capítulos que tratam da questão hídrica. A maioria dos livros didáticos analisados (6 livros) aborda a questão hídrica no volume 3. No entanto, 4 livros tratam a questão hídrica no volume 1 . O currículo do DF orienta trabalhar a ação antrópica na perspectiva da sustentabilidade, a cidadania e o cidadão no mundo e em sua comunidade no $1^{\circ}$ ano (BRASIL, 2013). Essa situação pode criar dificuldades na escolha do livro didático adequado, devendo o professor ficar atento a esse detalhe no momento da escolha do material.

Todos os livros didáticos analisados abordaram de forma explícita o ser humano como influenciador do ciclo da água (C1). Assim, encontra-se no Livro 3 o seguinte trecho:

Os poluentes são, quase sempre, resíduos de atividades humanas essenciais, como a agricultura, a indústria e a produção de resíduos biológicos (urina, fezes, por exemplo). [...] Os poluentes citados são resíduos naturais, pois decorrem da atividade humana e deverão aumentar à medida que a população cresce (JÚNIOR et al., 2017, p. 144).

Ao final do excerto mencionado, os autores acrescentam uma figura que complementa o que foi citado (Figura 1). Nela, apresenta-se uma área deteriorada pela ação humana, que despeja esgoto sem tratamento em um curso d'água, influenciando o ciclo da água e poluindo o pouco de água que se tem disponível. 
Figura 1: "Esgoto despejado no rio Paraíba do Sul, na cidade de Jacareí (SP), 2015. A coloração esverdeada do rio ocorre em razão da proliferação de algas e bactérias anaeróbicas" (JÚNIOR, 2017, p. 144).

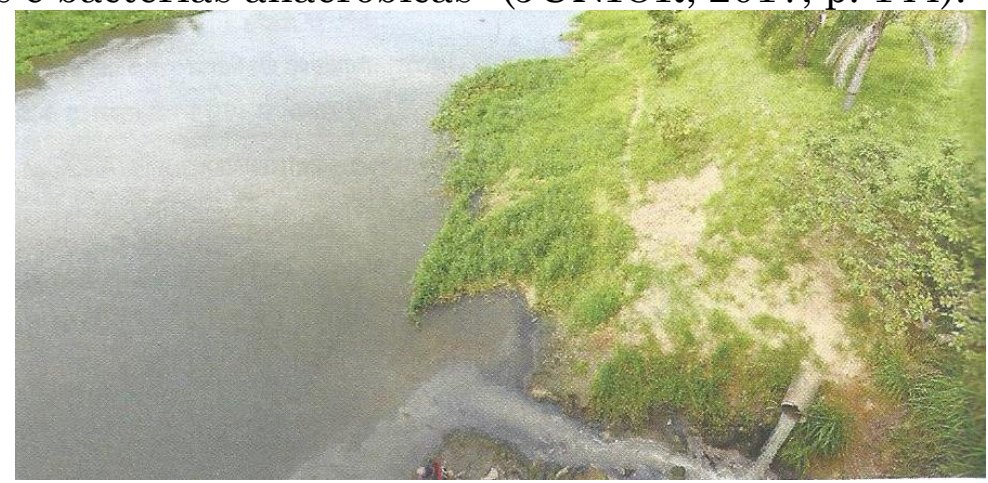

Fonte: Júnior (2017, p. 144)

Identificar o ser humano como influenciador do ciclo da água é importante, uma vez que é o mesmo o grande modificador do planeta. Esse resultado converge com o proposto pelo Currículo em Movimento e pela BNCC, pois, segundo esses documentos, o estudante deve ter uma visão de que o humano influencia, de alguma forma, na qualidade da água e, possivelmente, na disponibilidade desta:

[...] a natureza, o ser humano e a sociedade devem ser considerados de forma sustentável, por serem interdependentes. Além disso, esses três elementos vivem em constante transformação e, desse modo, é preciso que o trabalho pedagógico docente propicie que o estudante construa uma visão crítica sobre os processos de interação entre natureza, ser humano e sociedade. Nessa perspectiva, ações pedagógicas multiletradas contribuem para desvelar a ideologia erigida nas diversas representações do que se considera "sustentabilidade" (BRASIL, 2013, p. 56).

A BNCC ressalta a importância de analisar os ciclos biogeoquímicos e interpretar os efeitos de fenômenos naturais e da interferência humana de forma a promover ações individuais e/ou coletivas que minimizem consequências nocivas à vida (BRASIL, 2018). Galdino et al. (2018) 
corrobora refletindo que, em decorrência da interferência humana, há uma crise ambiental, sendo que esta corresponde à escassez dos recursos naturais e à poluição ambiental, com grandes consequências sociais.

Em nenhum livro didático, a influência do relevo sobre o ciclo da água (C2) é mencionada. Não abordar esse fator é limitar a compreensão da distribuição da água no território nacional, pois o relevo influencia a forma como a água é distribuída e a maneira como as pessoas a utilizam, por exemplo, para a agricultura (SANTOS et al., 2008; GUERRERO et al., 2018).

O critério que diz respeito à influência da ocupação do solo na preservação das nascentes (C3) está implícito nos Livros 2, 4, 5 e 6. Nestes, consta que a ocupação desordenada da população em áreas como rios e mangues pode vir a prejudicar a qualidade das águas, poluindo-as, mas não aborda a influência da ocupação do solo na preservação das nascentes. Como é mostrado no Livro 2: "nas grandes cidades litorâneas, por exemplo, a ocupação de áreas de manguezal traz uma série de problemas tanto para as pessoas como para o ambiente" (BIZZO, 2016, p. 272). Complementa a citação com a imagem de uma favela instalada em área de mangue no Recife, como mostra a Figura 2. Apresentar esse critério de forma implícita é esperar que o estudante consiga inferir sobre a questão da ocupação do solo, mas nem sempre o mesmo consegue. Em nenhum livro didático esse critério está explícito. Esse critério se encontra ausente nos Livros 1, 3, 7, 8, 9 e 10. 
Figura 2: Imagem que complementa a ocupação humana em regiões de mangues, podendo poluir às águas (BIZZO, 2016, p. 272).

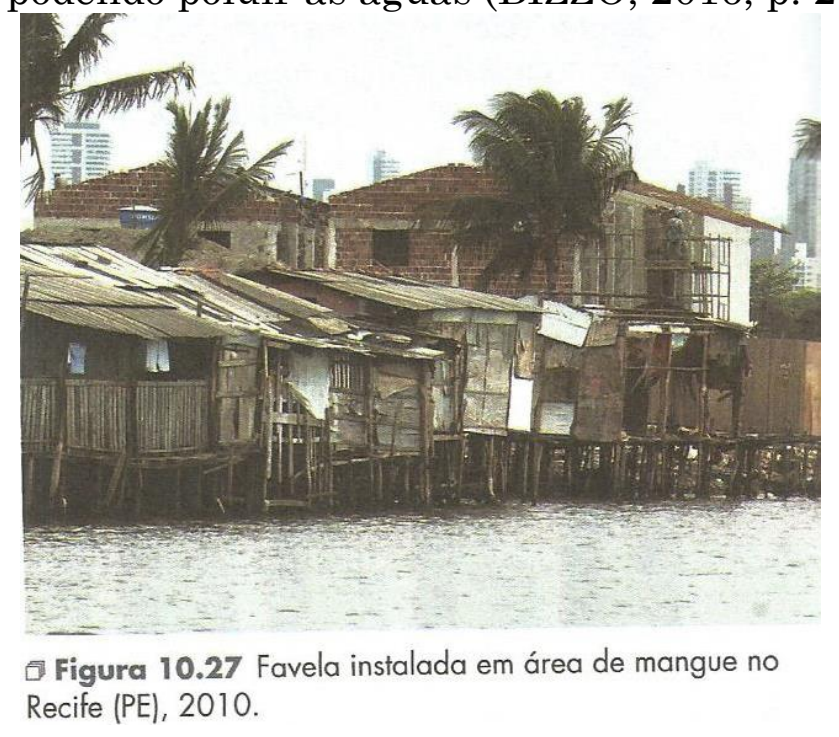

Fonte: Bizzo (2016, p. 272)

Tratar a ocupação do solo em regiões de nascentes é extremamente importante para o estudante entender que uma nascente origina cursos d'água, podendo estes serem grandes ou pequenos. Vale a pena ressaltar a importância da preservação da mata ciliar para maior conservação dessa área e da qualidade e disponibilidade da água. Em contrapartida, a falta de planejamento territorial e a exploração econômica empurram algumas populações para essas regiões vulneráveis, causando a poluição, contaminação e o exaurimento do recurso hídrico (SANTOS et al., 2003; SANTOS et al., 2008; GUERRERO et al., 2018).

A influência do crescimento da população no ciclo da água (C4), mostra-se explícita (VASCONCELOS; SOUTO, 2003) nos Livros 1, 2, 3, 4, 6 e 9. Por exemplo, no Livro 4:

[...] atualmente, a população mundial é de mais de 7 bilhões de habitantes e poderá ultrapassar 9 bilhões por volta de 2050. Essa imensa população e a crescente extração de recursos naturais, para atender a um consumo cada vez voraz, representam uma enorme pressão sobre o planeta como um todo (BANDOUK, 2016, p. 257). 
É curioso notar que tal critério está ausente nos Livros 5, 7, 8 e 10. Considerar o crescimento da população como influenciador do recurso hídrico é importante, uma vez que o aumento da população é diretamente proporcional à maior demanda de água. Barbosa (2014) também constatou a influência do tamanho da população nos recursos hídricos, afirmando que, diferentemente de outras populações animais, a sociedade moderna, com sua superprodução, superconsumo, crescimento populacional, apresenta uma carga excessiva para os sistemas aquáticos, capaz de interferir sobremaneira no ciclo da água, afetando sua oferta e disponibilidade.

A abordagem dos meios de economia da água (C5) é explícita nos Livros 1, 5, 6 e 7. No Livro 1, por meio do texto complementar "Alternativas energéticas" (AMABIS; MARTHO, 2016, p.279); no Livro 5, no decorrer do capítulo; no Livro 6 por meio do texto complementar "A escassez de água" (LINHARES, 2017, p. 230); e no Livro 7 aborda meios de economia de água e incita a participação do estudante com questões reflexivas sobre o assunto. Segue estes trechos como exemplo:

[...] baseando-se no conceito de pegada ecológica, qual seria o tamanho da sua pegada: pequena, média ou grande? Ela poderia ser considerada ecológica?"; "cite uma forma de reduzir o tamanho da sua pegada ecológica e converse sobre isso com os colegas" (OGO; GODOY, 2016, p. 257).

O interessante dessa questão é o fato de pôr os estudantes a pensarem na forma de economizar água e outros recursos naturais (reduzir sua pegada ecológica), não expondo, de imediato, maneiras de economia de água. Essa afirmativa entra de acordo com Martins e Guimarães (2002), pois, segundo eles, somente exibir meios de economia de água não adianta, é preciso fazer conexão com a ação humana e apresentar que o ciclo da água não é eterno, que esse recurso é finito, logo, não pode ser utilizado à vontade. 
O manual do professor dos livros 1,3 e 5 sugerem que a questão hídrica seja tratada de forma interdisciplinar, envolvendo outras disciplinas, como as de Geografia, História, Sociologia e Matemática, para que os estudantes não concebam a informação somente ao nível biológico. Essa abordagem é importante para o estudante conseguir ter visão da amplitude do problema. Diante disso, cabe ressaltar que o manual citado está disponível somente no manual do professor, não apresentando a possibilidade de abordagem hídrica interdisciplinar diretamente ao estudante. A abordagem de meios de economia de água não encontra-se presente nos Livros 2, 3, 4, 8, 9 e 10.

$\mathrm{O}$ critério que trata sobre a importância da gestão pública e da cidadania (C6) está explícita nos Livros 1, 4, 6 e 9. No Livro 1, está presente por meio do texto complementar "Água: um recurso cada vez mais precioso" (AMABIS; MARTHO, 2016, p. 202); no Livro 4, no decorrer do capítulo, abordando a cidadania como fator para a preservação dos recursos naturais, mas não contempla a responsabilidade da gestão pública; no Livro 9 , ao longo do texto, o critério é tratado com afirmativas, por exemplo "O abastecimento de água deve ser bem planejado e suas fontes preservadas" (MENDONÇA, 2016, p. 60); e no Livro 6, afirmando que "Cabe à sociedade, por exemplo, pressionar o governo a criar e fiscalizar medidas voltadas à proteção do meio ambiente e da saúde da população" (LINHARES et al., 2017, p. 277).

Esse critério apresenta-se implícito nos Livros 3 e 8; fazendo referência à cidadania por meio de texto complementar. Exemplificado no livro 8 por meio do texto "Pegada de água ou pegada hídrica" (LOPES; ROSSO, 2017, p. 86), mas não menciona a responsabilidade da sociedade na conservação e economia da água; não há nenhuma citação da responsabilidade do poder público e das políticas públicas a serem adotadas e da importância da fiscalização da população quanto às medidas necessárias para a conservação da água. O critério C6 está ausente no Livro $2,5,7$ e 10. 
Trazer a importância da gestão pública e da população na fiscalização e conservação do recurso hídrico é importante para transformar o estudante em um cidadão ativo e participativo diante da resolução dos problemas da sociedade, indo ao encontro do que é esperado a ser aprendido no Ensino Médio, segundo o Currículo em Movimento (BRASIL, 2013) e a BNCC (BRASIL, 2018). Galdino et al. (2018) corrobora, afirmando que é importante a compreensão do papel do cidadão na fiscalização do poder público, para que este desenvolva estratégias de planejamento e implementação de políticas públicas, normas viáveis para assegurar melhores condições e disponibilidade de água para a população.

Nossos dados mostram que há, nos livros didáticos, uma resistência em apontar a importância da gestão pública em políticas voltadas para a água e a responsabilidade dos cidadãos em preservar e fiscalizar as medidas necessárias para a conservação de tal recurso.

A reflexão sobre o que é crise hídrica (C7) não é encontrada explícita em nenhum dos livros didáticos analisados. Porém encontra-se implícito no Livro 5 e Livro 9, pois, em nenhum momento, é abordada claramente a crise hídrica, somente é exposto que o ser humano precisa preservar as reservas hídricas para não comprometer o acesso à água potável. Exemplificado no Livro 5, em que o tema é aludido por meio do texto "Transposição do rio São Francisco é tema de debate na Assembleia do RN" (FAVARETTO, 2016, p. 125); aqui expõe-se a questão da seca no sertão nordestino e a discussão entre os possíveis benefícios e malefícios decorrentes da obra de transposição do rio São Francisco, mas não explica o que é crise hídrica.

O mesmo critério está ausente em quase todos os livros: 1, 2, 3, 4, 6, 7, 8 e 10. Mas o manual do professor do livro 2 destaca fatos e ações relevantes. Frisa a importância de o estudante perceber como ocorre as relações dos seres vivos com o meio ambiente no decorrer do tempo e as modificações que as ações humanas provocam no ambiente. Além disso, o mesmo manual assevera que é importante o professor "evitar a falsa impressão de que o ciclo da água garante um estoque ilimitado para o consumo humano". 
(BIZZO, 2018, p. 349). Recomenda também, ao professor, trabalhar a questão da disponibilidade e qualidade da água doce, ressaltando que a despoluição é um processo demorado e complexo. Nesse ínterim, esse manual fornece, ao docente, fontes bibliográficas de artigos para apoio e enriquecimento do conhecimento acerca do tema.

Não apresentar reflexão sobre o que é crise hídrica é deficitário, pois não transmitir a ideia de que esse recurso está em crise pode iludir o estudante, permitindo-o pensar que a disponibilidade da água é ilimitada. Vieira (2017) complementa afirmando que limitar o pensar crítico do discente diante de problemas com os quais a sociedade se depara é assombroso, pois permite a formação de um sujeito sem autonomia e sem capacidade de participar de forma mais ativa em sua sociedade.

O que pode ser percebido durante a análise do conteúdo teórico é que os capítulos dos livros abordam a questão da ação humana mais no tocante à poluição das águas do que à crise hídrica propriamente. Os livros que abordam a questão hídrica em mais de um capítulo não apresentam vínculo entre um capítulo e o outro, dificultando que o aluno faça conexões sobre os temas trabalhados, contribuindo para a fragmentação do entendimento. $\mathrm{O}$ resultado da análise do conteúdo teórico pode ser visto no Quadro 4, a seguir.

Quadro 4: Resultado da quantidade de livros e a maneira como o conteúdo teórico sobre a questão hídrica é abordada nos livros didáticos.

\begin{tabular}{|c|c|c|c|}
\hline $\begin{array}{c}\text { Dimensão avaliada } \\
\text { nos livros didáticos } \\
\text { de Biologia PNLD } \\
\mathbf{2 0 1 8}\end{array}$ & Critérios em análise & $\begin{array}{c}\text { Estudo de cada } \\
\text { critério }\end{array}$ & $\begin{array}{c}\text { Quantidade de } \\
\text { livros }\end{array}$ \\
\hline \multirow{2}{*}{ Conteúdo teórico } & $\begin{array}{l}\text { C1. Identifica o ser humano como um } \\
\text { dos influenciadores do ciclo da água }\end{array}$ & I. Explícito & Todos os livros \\
\cline { 2 - 4 } & $\begin{array}{l}\text { C2. A influência do relevo sobre o ciclo } \\
\text { da ága }\end{array}$ & I. Ausente & Todos os livros \\
\cline { 2 - 4 } & $\begin{array}{c}\text { C3. Influência da ocupação do solo na } \\
\text { preservação das nascentes }\end{array}$ & I. Explícito & 0 \\
\cline { 2 - 4 } & II. Implícito & 4 \\
\hline
\end{tabular}




\begin{tabular}{|c|c|c|}
\hline & parcialmente & \\
\hline & III. Ausente & 6 \\
\hline \multirow{3}{*}{$\begin{array}{l}\text { C4. Influência do crescimento da } \\
\text { população }\end{array}$} & I. Explícito & 6 livros \\
\hline & II. Implícito & 0 \\
\hline & III. Ausente & 4 livros \\
\hline \multirow{3}{*}{ C5. Aborda meios de economia de água } & I. Explícito & 4 livros \\
\hline & II. Implícito & 0 \\
\hline & III. Ausente & 6 livros \\
\hline \multirow{3}{*}{$\begin{array}{l}\text { C6. Importância da gestão pública e } \\
\text { cidadania }\end{array}$} & I. Explícito & 4 livros \\
\hline & II. Implícito & 2 livros \\
\hline & III. Ausente & 4 livros \\
\hline \multirow{3}{*}{ C7. Reflexão sobre o que é crise hídrica } & I. Explícito & 0 \\
\hline & II. Implícito & 2 livros \\
\hline & II. Ausente & 8 livros \\
\hline
\end{tabular}

Fonte: Autores

Dentre os livros analisados, os que abordaram nas atividades propostas situações do cotidiano do estudante (C8) foram: Livro 5, 7, 8 e 9. Como exemplo, segue a atividade do Livro 5:

Pense nas atividades que realiza em seu dia a dia. Liste, no caderno, as atividades que envolvem o uso de combustíveis fósseis (derivados de petróleo e o carvão mineral), as que lançam poluentes na atmosfera ou na água e ainda aquelas que geram resíduos (OGO; GODOY,2016, p. 257).

O manual do professor do livro 5 orienta o professor explorar os conhecimentos prévios dos estudantes por meio de amostragem de desastres ambientais ocorridos no Brasil, como o de Mariana (MG), por meio de questionamentos, como "qual a origem da água disponível para o consumo 
em suas comunidade?”, “a que tipo de agravos ela está sujeita?” FAVARETTO, 2016, p. 337). O livro 7 propõe trabalhar em sala de aula o texto sobre saúde ambiental do Ministério da Saúde (2011), o qual visa a "antever, prevenir e monitorar efeitos de alterações ambientais sobre a saúde humana" (OGO, GODY, 2016, p. 350). O livro 9 sugere, ao professor, colocar os estudantes para observar o ambiente que vivem e/ou onde está localizada a escola, a fim de identificarem desequilíbrios ambientais e suas causas; há também a recomendação de que eles fotografem, façam vídeos, entrevistem moradores e depois reúnam-se em equipes para poderem propor ações para o enfrentamento de tais problemas, envolvendo toda a comunidade escolar (MENDONÇA, 2016). Já os Livros 1, 2, 3, 4, 6 e 10 não abordam situações do cotidiano dos estudantes. Exemplifica-se por meio da atividade do Livro 1:

A noção de desenvolvimento sustentável, ou sustentabilidade, refere-se a) À capacidade inesgotável dos recursos que sustentam a humanidade. b) À utilização dos recursos do ambiente tendo em mente sua preservação para gerações futuras.

c) À reinvindicação dos países em desenvolvimento de serem sustentados pelos países ricos. d) À ideia de que países ricos vêm sendo sustentados pelos recursos obtidos dos países pobres (AMABIS; MARTHO, 2016, p. 282).

No entanto alguns desses livros que não atendem ao critério 8 fazem algumas ressalvas pertinentes no manual do professor. $\mathrm{O}$ manual do professor do livro 2 apresenta questionamentos que possibilitam que o docente trabalhe a reflexão do estudante quanto ao seu conhecimento sobre a questão hídrica e possibilita que o discente o modifique ao longo das aulas, como: "como a ação humana alterou e altera o ambiente natural?"; "quais os ambientes naturais que você conhece?"; e "como podemos contribuir para diminuir a poluição?” (BIZZO, 2016, p. 352). 
No livro 4, é enfatizado que o professor precisa estimular o estudante a ser visto como sujeito ativo e fundamental na busca por soluções para os problemas que enfrentam. Sugere como atividades complementares: debate sobre mudanças climáticas e interpretação de tiras sobre questões ambientais, em que os estudantes terão que levar para a aula uma tira, quadrinhos ou cartuns de revistas, jornais ou da internet que tratem sobre temas ambientais. Esse material deve ser discutidos em sala e organizado em um grande cartaz para exposição (BANDOUK, 2016).

No livro 6, há, como sugestão de aula prática, a construção de um terrário pelos estudantes, para que nele possam ser observados os componentes bióticos e abióticos, o ciclo da água (LINHARES, GEWANDSZNAJDER, PACCA, 2016). Essa atividade prática poderia ser exposta no decorrer do capítulo, pois assim o estudante poderia fazer em casa, caso o docente não consiga trabalhar em sala esta prática.

Abordar situações do cotidiano auxilia na compreensão da problemática da água, pois permite que o estudante pense criticamente sobre as suas atitudes diante do consumo e da conservação de tal recurso. Em acordo com essa afirmativa, Culpi e Alves (2015) confirmam que o ensino de Ciências necessita ter caráter contextualizado, de modo a apresentar significado ao estudante. Quando os livros didáticos abordam a questão hídrica de forma mecânica, reproduzindo o que foi mencionado no decorrer do capítulo, pode não criar significado para o discente, dificultando, talvez, mudança de hábito dos estudantes.

A presença de proposta de atividades práticas (C9) encontra-se nos Livros 3, 4, 6 e 9. O Livro 4 apresenta a atividade "Compra, descarte, compre: uma reflexão sobre a sociedade de consumo" (BANDOUK, 2016, p. 287), em que propõe aos estudantes confeccionarem um jogo de tabuleiro. Com essa atividade os discentes podem compreender as etapas de produção industrial até o consumo de um produto. Já os Livros 1, 2, 5, 7, 8 e 10 não possuem proposta de atividades práticas. 
As atividades práticas são importantes para a melhor compreensão do tema e permite obter maior atenção dos estudantes no decorrer das aulas, dependendo, também, de como o professor orienta a prática. Dentro dessa análise, o professor necessita deixar claro para os estudantes "o que" e "como" será feita a prática. Araújo (2017) corrobora com o exposto ao dizer que a teoria em conjunto com a prática, buscando meios que possibilitem a construção do conhecimento com experiências do cotidiano, são importantes para a consolidação do processo de ensino aprendizagem.

Todos os livros didáticos apresentam questões/ exercícios ao longo de cada capítulo (C 10). Algo muito importante para a fixação do tema, ou de qualquer conteúdo, pois os exercícios permitem que o estudante reveja o que foi estudado de formas variadas e em diferentes situações. Os livros 4, 7 e 9 apresentam as questões e exercícios ao longo do capítulo e não somente ao final, como nos livros 1, 2, 3, 5, 6, 8 e 10.

O enfoque das questões encontra-se multidisciplinar (C11) nos Livros 6, 7, 8 e 9, porque o estudante precisa do conhecimento de matemática para a compreensão dos gráficos expostos nos exercícios. Os Livros 1, 2, 3, 4, 5 e 10 possuem o enfoque das questões unicamente biológico, não necessitando de outras disciplinas para a compreensão e resolução das questões. Mas a questão hídrica não pode ser abordada unicamente com enfoque biológico, pois assim é simplificar muito o tema. O pensamento de Pinto (2017) vai de acordo com o afirmado, pois o aumento na demanda de água doce pelas sociedades tem impactos sociais, políticos e econômicos.

Os livros que priorizam a problematização das questões (C12) são: Livros 1, 3, 4, 5, 7, 8 e 9. Como exemplo, há no Livro 4 a seguinte questão:

O rompimento da barragem que causou o desastre ecológico citado no texto ocorreu em novembro de 2015. Procure por informações atualizadas e relate a situação do município de Mariana e do rio Doce atualmente. (BANDOUK, 2016, p. 277) 
Os Livros 2, 6, e 10 não priorizam a problematização nas questões. A maioria dos livros didáticos propõe questões com problematização e isso permite a formação do cidadão crítico, consciente da sociedade em que está inserido, sendo capaz de transformar sua realidade e construir seu próprio conhecimento. A presença desse critério está de acordo com o estabelecido pelo Currículo em Movimento (BRASIL, 2013) e pela BNCC (BRASIL, 2018), que dispõem sobre a matriz curricular do Ensino Médio.

Os livros que requerem recursos de fácil obtenção para as atividades práticas (C13) são: Livros 3, 4, 6 e 9. Como exemplo, cita-se o Livro 3, que tem como atividade prática investigar a poluição das águas na região que o estudante vive, necessitando somente o material de escrita e o meio para o deslocamento até o local de rios (JÚNIOR, 2017). Essa locomoção pode ser feita por meio de transporte fornecido pela escola ou a atividade prática pode ser desenvolvida somente pelos estudantes, como pesquisa autônoma, eles se responsabilizando por chegar ao local a ser investigado. Por ser uma prática a ser desenvolvida por adolescente, logo a locomoção não seria um empecilho. Os Livros 1, 2, 5, 7, 8 e 10 não possuem atividades práticas propostas. Todos as atividades propostas pelos livros didáticos estão relacionadas com o conteúdo trabalhado no capítulo (C14).

\section{Conclusão}

Os livros didáticos são instrumentos que podem auxiliar professores e estudantes na aprendizagem. A presente pesquisa buscou verificar e discutir a abordagem hídrica nos livros didáticos.

Percebe-se que a educação ambiental na escola é um componente importante na sociedade contemporânea, visto que a exploração dos recursos hídricos é cada vez mais intensa e a sua disponibilidade é proporcionalmente inversa.

Diante disso, a abordagem hídrica precisa se voltada para uma educação ambiental (EA) libertadora e dialógica. Esta forma pedagógica possibilita o estudante e o educador o abandono do pensar ingênuo que é a 
normalização da realidade, para o desenvolvimento do pensar crítico e questionador da atualidade.

Nesse sentido, a escola para desenvolver uma EA crítica deve buscar meios de sensibilização social e ambiental, mudança de valores e atitudes tanto dos estudantes quanto dos docentes. Isto releva que a educação ambiental necessita ser ampla e reflexiva, de forma que transforme tanto o pensar do educando quanto do educador para a questão socioambiental.

Nossos dados mostram que todos os livros analisados identificam o ser humano como um dos influenciadores do ciclo da água e isto possibilita ao estudante construir um conhecimento contextualizado, podendo prepará-lo para fazer julgamentos e discussões éticas, socioculturais, políticas e econômicas, o que está de acordo com a BNCC.

Uma das constatações verificadas nessa pesquisa é a total ausência, no conteúdo teórico, da influência do relevo sobre o ciclo da água nas dez obras analisadas. A abordagem deste ponto permitiria construir conhecimentos acerca do relevo do Cerrado, no caso do Distrito Federal, que possui uma particularidade na composição do solo e da vegetação nativa, importantes para a captação e distribuição da água para outras regiões do Brasil. Não abordá-lo é limitar a compreensão da complexidade do Cerrado e, assim, negligenciar a necessidade da preservação das nascentes para manter a disponibilidade e qualidade da água, outro critério ausente na maioria das obras analisadas.

Outra tendência verificada nos livros didáticos é que, apesar da maioria deles abordarem a influência do crescimento da população na extração dos recursos naturais, mais da metade das obras não apresentam meios de economia de água e também não fazem os estudantes refletirem sobre o que é a crise hídrica, trazendo o conteúdo com pouca análise da influência humana quanto à disponibilidade da água. Essa carência dos livros não contribui para a formação da responsabilidade ambiental. 
A pesquisa identificou que os livros didáticos apresentam pouca abordagem interdisciplinar, que as atividades presentes nos capítulos não abordam situações do cotidiano do estudante.

\section{Referências}

ADASA. Agência Reguladora de Águas, Energia e Saneamento Básico do Distrito Federal. Níveis oficiais dos reservatórios. Distrito Federal, 2016. Disponível em: < http://www.adasa.df.gov.br/monitoramento/niveis-dos-

reservatorios/monitoramento/niveis-dos-reservatorios/796-nivel-dos-reservatorios>. Acesso em: 14, abr. 2018.

AMABIS, J. M.; MARTHO, G. R. Biologia moderna. Volume 3, Ensino Médio. $1^{\text {a }}$ ed. São Paulo: Moderna, 2016.

ARAUJO, F., C., M., D. Produção do livro paradidático: uma pitada de sal no ensino de Geografia. Rio Grande do Norte: Universidade Federal do Rio Grande do Norte, 2017, p. 144.

BANDOUK, A. C. Ser protagonista: Biologia. Volume 3, Ensino Médio. $3^{\text {a }}$ ed. São Paulo: SM, 2016.

BARBOSA, V. Torneira seca? A crônica paulista de uma crise anunciada. In: $A$ última gota. São Paulo: Planeta, cap. 1, p. 41 - 62, 2014.

BIZZO, N. Biologia: novas bases. Volume 3, Ensino Médio. 1ª ed. São Paulo: IBEP, 2016.

BRASIL. Base Nacional Comum Curricular. BNCC. Ministério da educação, 2018. Disponível em:< http://basenacionalcomum.mec.gov.br/wpcontent/uploads/2018/04/BNCC_EnsinoMedio_embaixa_site.pdf $>$. Acesso em: 17, abr. 2018.

- Ministério do Meio Ambiente. Identidade da Educação Ambiental Brasileira. Diretoria de Educação Ambiental. Brasília, p. 156, 2004.

Secretaria de Estado de Educação do Distrito Federal. Currículo em Movimento da Educação Básica - Ensino médio. Brasília, 2013.

CULPI, V., L., F., L. Contribuições da Pegada Hídrica no Ensino de Ciências: Percepções e Perspectivas de Mudança a partir da Sala de Aula. Paraná: Universidade Teológica Federal do Paraná, 2016.

FAVARETTO, J. A. Biologia: unidade e diversidade. Volume 3, Ensino Médio. $1^{\text {a }}$ ed. São Paulo: FTD, 2016.

FREIRE, P. Pedagogia do oprimido. Rio de Janeiro: Paz e Terra, 60ª edição, 2016. 
GALDINO, S., M.; SOUSA, R., M., R.; COSTA, S., M., G.; FERREIRA, P., C. Estudo prospectivo de Tecnologias Potenciais para a Solução da Crise Hídrica no Brasil. Cad. Prospec. Salvador, v. 11, Edição Especial, p.198-210, 2018.

GOMES, R., K., S.; NAKAYAMA, L. Educação ambiental: saberes necessários a práxis educativa docente de uma escola amazônica amapaense. Educar em Revista. Curitiba, v. 33, n. 66, p. 257-273, 2017.

GUERRERO, J., V., R.; LOLLO, J., A.; MOSCHINI, L., E.; LORANDI, R. Carta de fragilidade ambiental como instrumento de planejamento e conservação de unidades aquíferas: o caso da bacia do rio Clarinho, SP. Caderno de Geografia. Minas Gerais, v. 25, n. 53, p. 385-403, 2018.

JÚNIOR, C. S.; SASSON, S.; JÚNIOR, N. C. Biologia. Volume 1, Ensino Médio. $12^{a}$ ed. São Paulo: Saraiva, 2017.

LINHARES, S.; GEWANDSZNAJDER, F; PACCA, H. Biologia Hoje. Volume 3, Ensino Médio. $3^{\text {a }}$ ed. São Paulo: Ática, 2016.

LOPES, S.; ROSSO, S. Bio. Volume 1, Ensino Médio. $3^{\text {a }}$ ed. São Paulo: Saraiva, 2017.

MARTINS, E; GUIMARÃES, G. As concepções de natureza nos livros didáticos de ciências. Ensaio. México, v. 4, n. 2, p. 1-14, dez. 2002.

MENDONÇA, V. L. Biologia. Volume 1, Ensino Médio. 3ª ed. São Paulo: AJS, 2016. OGO, M.; GODOY, L. \# Contato Biologia. Volume 3, Ensino Médio. $1^{\text {a }}$ ed. São Paulo: Quinteto, 2016.

OTALARA, A., P.; CARVALHO, L., M. O tema água nos livros didáticos de ciências da natureza, o cotidiano (global - local) e as questões ambientais. VI Encontro "Pesquisa em Educação Ambiental". A pesquisa em educação ambiental e a pósgraduação no Brasil. Ribeirão Preto, 2011.

PASSERIA, M., G.; AIRES, R., M.; ROCHA, M., B. Reelaboração discursiva de um texto de divulgação científica sobre crise hídrica em um livro didático de ciências. Ensino, saúde e ambiente. Rio de Janeiro, v. 10, n. 1, p. 142-162, 2017.

PINTO, E. Geopolítica da água. Revista de Geopolítica. Natal, v.8, n.1, p. 19-32, 2017.

SANTOS, A., C.; SALCEDO, I., H.; CANDEIAS, A., L., B. Relação entre o relevo e as classes texturais do solo na microbacia hidrográfica de Vaca Brava, PB. Revista Brasileira de Cartografia, n., 54, p. 86-94, 2003.

SANTOS, A., C.; SALCEDO, I., H.; GALVÃO, S., R., S. Relações entre o uso do solo, relevo e fertilidade do solo em escala de microbiota. Revista Brasileira de Engenharia Agrícola e Ambiental. Campina Grande, PB, v. 12, n. 5, p. 458-464, 2008 . 
SILVA, R. Tema água: uma contribuição para o desenvolvimento de percepções, questionamentos e compromissos sociais. Brasília: UnB. 2016. 144 p.

SILVA, T., R; SILVA, B., R. Reflexões sobre a abordagem de ciclos biogeoquímicos no ensino em ciências: considerações para um enfoque em CTS. Revista do Plano Nacional de Formação de Professores da Educação Básica. Universidade Federal do Piauí, Teresina, v. 5, n. 2, p.5-18, 2017.

SOUZA, P; ROCHA, M. A análise da linguagem de textos de divulgação científica em livros didáticos: contribuições para o ensino de Biologia. Atlas do IX encontro Nacional de Pesquisa em Educação em Ciências. São Paulo, v. 23, nº 2, p. 321-340, 2017.

VASCONCELOS, S. D.; SOUTO, E. O livro didático de ciências no ensino fundamental - proposta de critérios para análise do conteúdo zoológico. Ciência \& Educação. São Paulo, v. 9, n. 1, p. 93 - 104, 2003.

VIEIRA, E., P., B. A crise hídrica no distrito Federal: uma proposta CTS em rede social sobre o processo de separação de materiais. Brasília: UnB, 2017, p. 161.

Recebido em setembro de 2019.

Aprovado em janeiro de 2020. 